
About IJMA [last updated July, $\left.1^{\text {st }}, 2021\right]$

$\checkmark$ International Journal of Medical Arts is the Official Journal of the Damietta Faculty of Medicine, AlAzhar University, Egypt

$\checkmark$ It is an International, Open Access, Double-blind, Peer-reviewed Journal

$\checkmark$ Published four times a year

$\checkmark$ The First Issue was published in July 2019

$\checkmark$ Published under the following license: Creative Commons Attribution-ShareAlike 4.0 International Public License (CC BY-SA 4.0). It had updated from the Creative Commons license [CC BY] in volume 2, Issue 4, October 2020 About IJMA

$\checkmark$ The Egyptian Knowledge Bank hosts the web site of IJMA

$\checkmark$ The Egyptian Knowledge Bank supports IJMA

$\checkmark$ IJMA follows the regulations of the International Committee of Medical Journal Editors

$\checkmark$ IJMA is indexed in the "Directory of Open Access Journals" [15 January 2021].

$\checkmark$ IJMA is indexed in JGate [29-6-2021]

$\checkmark$ IJMA is a member of the International Society of Managing and Technical Editors

$\checkmark$ Listed in "Index Copernicus", "Publons", "Academic resource index [ResearchBib]", "Electronics journal library", "Eurasian Scientific Journal Index", and "Citefactor"

$\checkmark$ IJMA introduced to the search engine [BASE] through DOAJ
Click image to reach the page

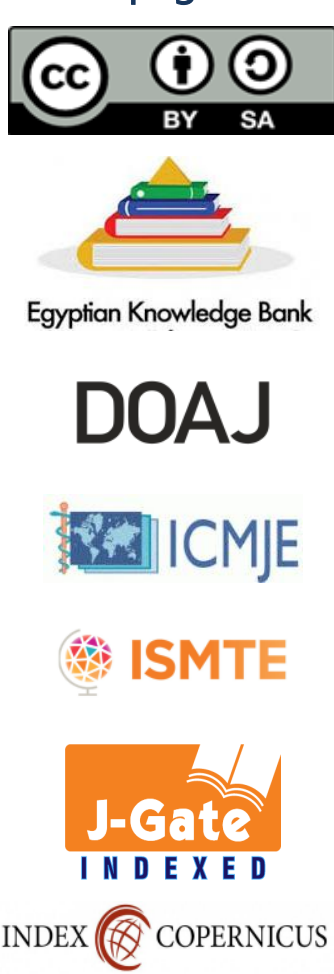

publons

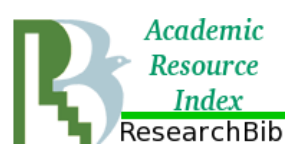

\section{EZ3 \\ .}

ESJII

CiteFactor

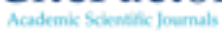

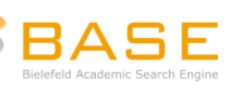




Available online at Journal Website
https://ijma.journals.ekb.eg/
Main subject [Orthopedic Surgery]

Original Article

\title{
Triceps Sparing Approach for Fixation of Distal Humerus Fractures in Adults
}

\author{
Mohamed Ahmed Safy. \\ Department of Orthopedics, El-Mataria Teaching Hospital, Ministry of Health, Egypt. \\ Email: mohamedsafyeldeen123@gmail.com.
}

Submission date: June 04, 2021; Acceptance date: July 14, 2021.

DOI: $10.21608 /$ ijma.2021.80438.1325

\section{ABSTRACT}

Background: Distal humerus fractures had acquired an attention due to poor outcomes regardless of treatment modality which may be conservative or surgical. These fractures can be addressed with either triceps splitting or triceps sparing approach. The triceps sparing approach was performed by lateral window was developed on the lateral side of the triceps as it is elevated off the posterior border of the intermuscular septa and posterior humerus.

Objective: The current work aimed to evaluate the outcome of surgical treatment of fracture distal humerus through triceps sparing approach.

Patients and methods: A prospective, descriptive clinical study had been conducted at the Department of Orthopedic Surgery [Al Mataria Teaching Hospital, Egypt]. The study included 33 patients, and the average follow up was 12 months. The study completed from December 2018 to May 2020. Pain, clinical and radiological outcomes had been assessed and documented. Preoperatively, all patients had been clinically and radiologically evaluated. In addition, laboratory investigations had been performed to assess the fitness of the patient.

Results: The study participants were 25 males and 8 females. Their age ranged between 30 and 55 years [mean age $43.09 \pm 7.93$ years]. The mean quick Disabilities of the Arm, Shoulder and Hand [DASH] score was 18.3 \pm 3.3 points [ranged between 15 and 25]. The mean range of elbow flexion was $143.3 \pm 3.9$ degrees [135-145], while the mean range of elbow extension and contracture $8.6 \pm 1.7$ degrees [6-15]

Conclusions: Triceps sparing avoids direct triceps injury with bloodless fields. However, a limited articular surface visualization of the distal humerus is an evitable drawback.

Keywords: Total Elbow Arthroplasty; Distal humerus; fixation; Triceps sparing; Fractures.

This is an open-access article registered under the Creative Commons, ShareAlike 4.0 International license [CC BY-SA 4.0] [https://creativecommons.org/licenses/by-sa/4.0/legalcode.

Citation: Safy MA. Triceps Sparing Approach for Fixation of Distal Humerus Fractures in Adults. IJMA 3 [3] July-September: 1719-1723. [DOI: 10.21608/ijma.2021.80438.1325].

* Main subject and any subcategories have been classified according to the research topic. 


\section{INTRODUCTION}

Distal humerus fractures are a challenging condition, due to its poor outcome regardless of conservative or surgical treatment modalities ${ }^{[1]}$. These fractures are most often the result of direct [e.g., direct blow to the affected limb] or indirect trauma [e.g., foreign object or fall on the ground]. In addition, high-energy mechanisms are due to a motor car or motorcycle accident. Distal humerus fractures have also even been reported in cases of projectile injury. Patient age is usually an incorporating factor in whether the mechanism is of low- or high-energy [2].

The conservative treatment achieved by the cast immobilization. However, surgical treatment provides more predictable alignment and a quicker return to function. These fractures can be managed by triceps splitting or sparing approaches ${ }^{[3]}$.

The triceps sparing approach is associated with low intramuscular adhesion and scar formation. It theoretically lower the potential for elbow contracture and enhances the post-operative triceps function ${ }^{[4]}$.

Triceps sparing technique escapes direct triceps trauma and performed with bloodless planes. This is the principal cause for improved elbow range of motion [ROM] and less postoperative contractures of the elbow ${ }^{[3]}$.

Here we presented our clinical experience with triceps sparing approach for distal humerus fractures. We expected better and improvement outcome.

\section{AIM OF THE WORK}

The current work aimed to evaluate the results of surgical intervention for distal humerus fractures through triceps sparing approach.

\section{PATIENTS AND METHODS}

This was a prospective, descriptive, clinical study, included 33 patients [convenient sample], presented with fracture distal humerus. All were selected from El-Mataria Teaching Hospital, Ministry of Health, Egypt. The study completed between December 2018 to May 2020.

The age ranged between 30 and 55 years. The mechanism of injury was road traffic accidents [RTA] and falling on the ground [FOG]. Every patient was instructed about the study and signed a written informed consent for participation [available on request].

His/her privacy, confidentiality and withdrawal right were guaranteed. Additionally, the administration and research ethics committee approval was obtained [IRB\#00012367-31-9-2018].

The exclusion criteria were open fractures, intra articular fractures of distal humerus, pathological fractures and surgically unfit.

Preoperative evaluation consisted of inquiry about all medical history data, a detailed clinical examination [general and local examinations] and standard laboratory investigations. A plain x-ray [figure 1] was the preoperative radiological assessment method.

Surgical technique: A broad-spectrum antibiotic was administered as a prophylactic drug, one hour preoperatively. All operations were completed under general anesthesia. The patient was positioned in the lateral decubitus position. The injured arm was supported to permit elbow flexion of at least $90^{\circ}$. Then, an extensile midline posterior skin incision, curving laterally around the olecranon, was performed. The fascia over the triceps brachii was recognized, splitted in the midline, and raised enblock with the dermis and subcutaneous tissues. The triceps was separated from the posterior aspect of the intermuscular septum. Laterally, the radial nerve with concomitant vessels were recognized. The posterolateral aspect of the humeral shaft was reached by the triceps muscle elevation and medial retraction from the posterior periosteum. Medially, the ulnar nerve was identified and exposed proximally in the posterior compartment. Distally, the ulnar nerve was released from the cubital tunnel and dissected to its first branch. Medial paratricipital dissection through the intermuscular septum posterior border exposes the posteromedial aspect of distal humerus. Connection of the medial and lateral dissections by mobilization and triceps elevation from the fracture and posterior periosteum permits visualization of the whole posterior distal humerus [figure 2]. Fracture reduction was performed with internal fixation with anatomical locked plate for distal humerus. The wound was closed in layers over a drain, which was removed after 48 hours.

Post-operative care and follow up: The arm was held in a pouch arm sling. Postoperative intravenous broadspectrum antibiotic for 72 hours was given, then oral for 4 days. Stitches were removed after 2 weeks. A wellstructured rehabilitation program was followed that was begun from the third post-operative day. The immobilizer was used for 2 to 4 weeks postoperatively. All patients had been evaluated clinically at discharge, at six and twelve postoperative months. The radiological outcome had been carried out at 2, 6 and 12 weeks, then after 6 and 12 months [Figures 3 to 5]. 
The evaluation done according to the Quick Disabilities of the Arm, Shoulder and Hand [DASH] system [5].

Statistical analysis: The collected data were coded [anonymized], and fed to personal computer through Microsoft excel software. Then, transferred to the statistical package for social science [SPSS] for windows, version 16

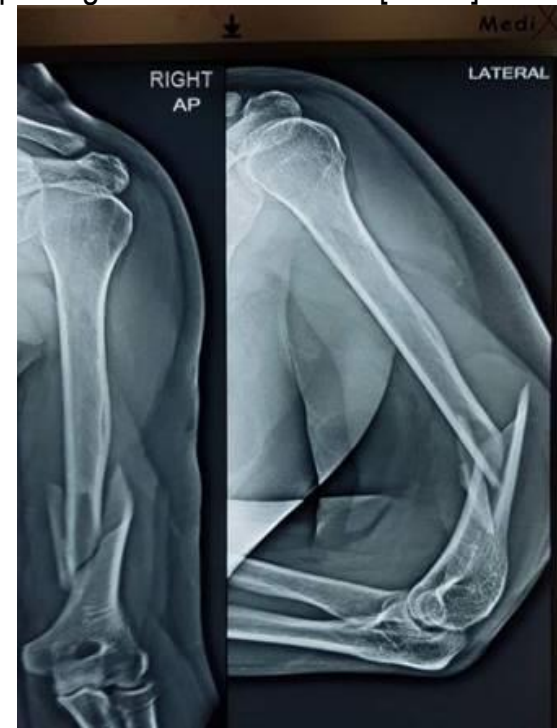

Figure [1]: Preoperative -ray showed distal humera fracture

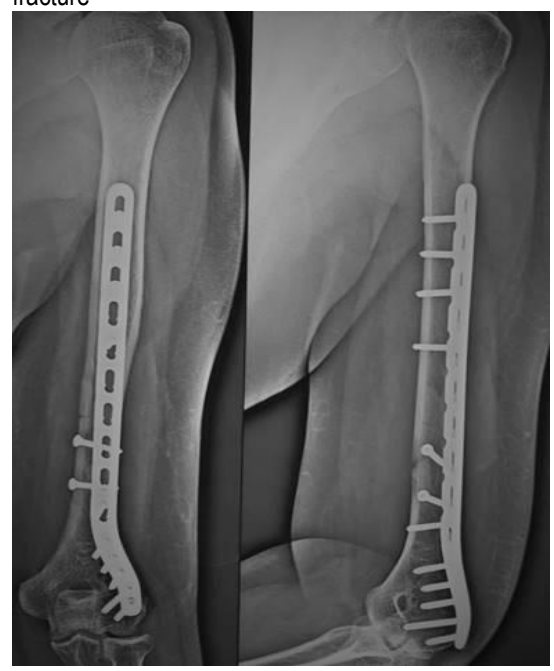

Figure [4]: Last follow up X-ray of the same patient

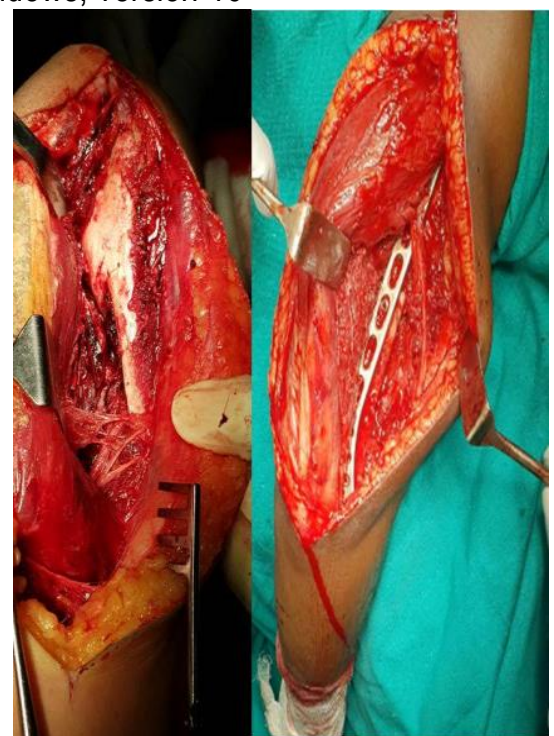

Figure [2]: Operative image showing exploration and previous prosthesis

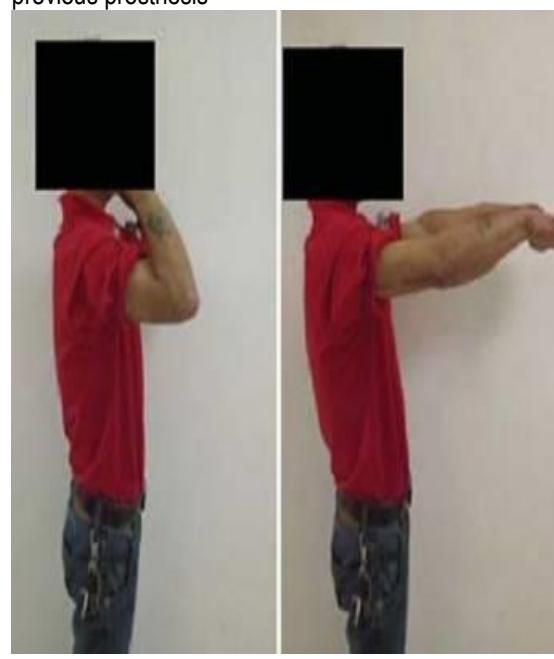

Figure [5]: Last follow up clinical image reflecting ROM at the elbow

\section{RESULTS}

The current work included 33 patients $[25$ males and 8 females]. The mean age was $43.09 \pm 7.93$ years [ranging between 30 and 55 years]. There were 8 housewives, 14 workers, 5 farmers, and 6 employees. The mean intraoperative blood loss was $346.36 \pm 60.71$ [250-450cc]. The mean operative time was $92.72 \pm 15.81$ minutes [70120]. The mean quick DASH score was $20.87 \pm 3.17$ points
[SPSS Inc., Chicago, USA]. The qualitative variables were presented in the form of their relative frequency and percentages, while quantitative data were presented as mean, and standard deviations. In addition, minimum and maximum values were calculated as an indication of the range.

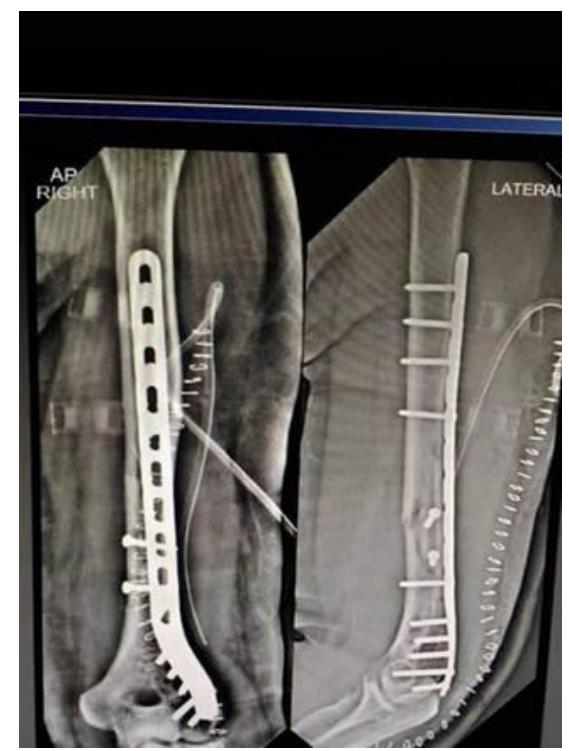

Figure [3]: Immediate postoperative x-ray showed a good fracture fixation
[15 to 25]. The mean range of elbow flexion was $140.45 \pm 3.82$ degrees [135-145]. The mean range of elbow extension and contracture 9.96 \pm 2.98 degrees [6-15] [Table 1]. Radiological outcome revealed that, union achieved in all patients. The mean time of bone union was $14.8 \pm 0.72$ weeks [12-20]. There were no non-union.

Regarding complications, there was one superficial wound infection [3.03\%] that resolved with debridement and antibiotics. 


\begin{tabular}{|c|c|c|}
\hline \multicolumn{3}{|c|}{ Table [1]: Data of studied patients } \\
\hline \multirow{2}{*}{\multicolumn{2}{|c|}{$\begin{array}{l}\text { Variable } \\
\text { Age [mean } \pm S D \text { ]; min. - max. }\end{array}$}} & Statistics \\
\hline & & $43.09 \pm 7.93 ; 30-55$ \\
\hline \multirow{2}{*}{$\begin{array}{l}\text { Sex } \\
{[n, \%]}\end{array}$} & Male & $25[75.8 \%]$ \\
\hline & Female & $8[24.2 \%]$ \\
\hline \multirow{2}{*}{$\begin{array}{l}\text { Mecahnism of injury } \\
{[n, \%]}\end{array}$} & RTA & $15[45.5 \%]$ \\
\hline & FOG & $18[54.5 \%]$ \\
\hline \multicolumn{2}{|l|}{ Intraoperative blood loss [ml] [mean \pm SD]; min. - max. } & $346.36 \pm 60.71 ; 250-450$ \\
\hline \multicolumn{2}{|l|}{ Operative time [minutes] [mean \pm SD]; min. - max. } & $92.72 \pm 15.81 ; 70-120$ \\
\hline \multicolumn{2}{|l|}{ DASH score [mean \pm SD]; min. - max. } & $20.87 \pm 3.17 ; 15-25$ \\
\hline \multicolumn{2}{|l|}{ Elbow flexion [o] [mean \pm SD]; min. - max. } & $140.45 \pm 3.82 ; 135-145$ \\
\hline \multicolumn{2}{|l|}{ Elbow extension [0] [mean \pm SD]; min. - max. } & $9.96 \pm 2.98 ; 6-15$ \\
\hline \multirow[t]{2}{*}{ Complications } & Yes & $1[3.03 \%]$ \\
\hline & No & 32 [96.97\%] \\
\hline
\end{tabular}

RTA: road traffic accident; FOG: Falling on the ground; DASH: Disabilities of the Arm, Shoulder and Hand

\section{DISCUSSION}

Because long-term elbow immobilization leads to stiffness, the conservative management protocols in distal humeral fractures play a role for inoperable geriatrics ${ }^{[6]}$. The dispute for a triceps-sparing rather than a triceps-splitting [detaching] approach used in young active adults with distal humerus fracture was further reinforced by the expanded elbow range of motion $[R O M]$ as well as preservation of the triceps strength that has been shown in the muscle-sparing technique ${ }^{[7]}$.

The two techniques provided a good-enough access for fracture reduction, fixation and application of 90/90 or parallel fixation plates ${ }^{[8]}$.

In the current study, ORIF was applied for 33 patients with distal humerus fractures through triceps-sparing approach. The mean elbow flexion was $140.45 \pm 3.82$ degrees [135-145], and the mean elbow extension was $9.96 \pm 2.98$ degrees [6-15]. Radiological outcome was achieved in all patients. The mean time of bone union was $14.8 \pm 0.72$ weeks [12-20].

Yorukoglu et al. ${ }^{[9]}$ reported that, the general function of affected extremity [DASH-T] was perfect [27.14 \pm 25.66$]$, and the performance of elbow joint was good, after using distal medial locking plates for extra-articular distal humeral fractures. Additionally, Ali N. et al. ${ }^{[10]}$ reported that mean flexion at elbow was $127 \pm 12.07^{\circ}$ [95 to 145 ] and all the patients had flexion extension arc movement of more than 1000 at the elbow joint at final follow up.

Furthermore, Illical et al. [11] proved that the triceps sparing is associated with better ROM of the elbow than the triceps-detaching approach, with significant improvement of elbow flexion and reduced extension contracture. The triceps strength also favored the triceps-sparing approach when compared to healthy arm.
Jagdeep et al. [3] reported that, the mean time of bone union was $11.8 \pm 2.8$ in triceps splitting, and $12.0 \pm 3.6$ months in triceps sparing with non-significant difference. The mean elbow flexion was $140.0 \pm 4.0$ and $126.0 \pm 10.0$ in triceps sparing and triceps splitting groups respectively, with significant difference. Extension contracture was also significantly lower in triceps sparing than triceps splitting [5.0 \pm 6.0 vs $24.0 \pm 8.0]$. In this study, the mean quick DASH score was $18.3 \pm 3.3$ points [15 to 25]. Illica et al. [11] reported that, the mean DASH score was [14.45 \pm 12.17$]$ in triceps sparing. Jagdeep et al. [3] reported that, the mean DASH score was [24.28 \pm 10.14$]$ in triceps sparing.

More recently, Solarz et al. [12] reported that, the functional strength and DASH scores were significantly better in the triceps sparing than triceps detaching techniques. However, the range of motion, and postoperative pain were comparable between both techniques. They concluded that, triceps sparing preserve postoperative triceps function and strength after revision surgery, regardless of the approached used in previous surgeries.

In pediatrics, Kokly et al. [13] reported that, triceps sparing is an effective and safe approach who preserved the extensor mechanism with no ulnar nerve injury, acceptable cosmetic appearance of the scar with postoperative satisfactory function.

A meta-analysis by Lu S, et al. [14] concluded that, triceps-sparing approach is superior to olecranon osteotomy, regarding the operative duration, blood loss, and complications. Both techniques were comparable regarding excellent/elbow function.

Most recently and reflecting the important of the current work, Meijering et al. [15] registered a large trial to establish a consensus on the ideal approach for total elbow arthroplasty [triceps sparing vs. triceps detaching]. They 
suggested that, no consensus is present on the best surgical approach. Their results will greatly add to the available evidence.

Finally, Zhang et al. [16] found a better functional outcome for $\mathrm{C} 1$ and $\mathrm{C} 2$ distal humerus fractures using the triceps sparing rather than olecranon osteotomy.

The limiting steps of the current work included the small number of included cases and absent comparative group. These shortages prevent globalization of the results. However, results added to the available evidence, supporting the use of triceps sparing approach, especially for the rate of union [effectiveness] and low or absent complications [safety].

In conclusion, triceps sparing for distal humeral fractures avoids direct injury of triceps muscle and assures bloodless planes. However, a limited field visualization is an evitable drawback. This approach is associated with better ROM at the elbow joint and less extension contractures.

\section{Financial and Conflict of interest disclosure}

None

\section{REFERENCES}

1. Meloy GM, Mormino MA, Siska PA, Takin IS. A paradigm shift in the surgical reconstruction of extra-articular distal humeral fractures: single-column plating. Injury. 2013 Nov; 44[11]:1620-4. [DOI: 10.1016/j.injury.2013.07.005].

2. Crean TE, Nallamothu SV. Distal Humerus Fractures. 2020 Jul 20. In: StatPearls [Internet]. Treasure Island [FL]: StatPearls Publishing; 2021 Jan-. [PMID: 30285369].

3. Singh J, Kalia A, Dahuja A, Bansal K. Functional Outcomes after Triceps Splitting versus Triceps Sparing Approach for Extra-Articular Distal Humerus Fractures. Open J Orthoped. 2018; 8 [3]: 85-94. [DOI: 10.4236/ojo.2018.83011].

4. Kharbanda Y, Tanwar YS, Srivastava V, Birla V, Rajput A, Pandit R. Retrospective analysis of extra-articular distal humerus shaft fractures treated with the use of pre-contoured lateral column metaphyseal LCP by triceps-sparing posterolateral approach. Strategies Trauma Limb Reconstr. 2017 Apr; 12[1]:1-9. [DOI: 10.1007/s11751-016-0270-6].

5. Beaton DE, Wright JG, Katz JN; Upper Extremity Collaborative Group. Development of the Quick DASH: comparison of three item-reduction approaches. J Bone Joint Surg Am. 2005 May; 87[5]:1038-46. [DOI: 10.2106/JBJS.D.02060].

6. Dey Hazra RO, Lill H, Jensen G, Imrecke J, Ellwein A. Fracturepattern-related therapy concepts in distal humeral fractures. Obere Extrem. 2018; 13[1]:23-32. [DOI: 10.1007/s11678-0180442-8].
7. Ayoub MS, Tarkin IS. Best care paradigm to optimize functionality after extra-articular distal humeral fractures in the young patient. J Clin Orthop Trauma. 2018 Mar; 9[Suppl 1]: S116-S122. [DOI: 10.1016/j.jcot.2018.02.002].

8. Dacombe PJ, Clarke AM, Amirfeyz R. Modified bilaterotricipital approach to the distal humerus: a triceps preserving technique. Shoulder Elbow. 2016 Jul;8[3]:199-202. [DOI: 10.1177/1758573216647908].

9. Yorukoglu AC, Demirkan AF, Buker N. Distal medial tibial locking plate for fixation of extraarticular distal humeral fractures; an alternative choice for fixation. Acta Orthop Traumatol Turc. 2018 Jul; 52[4]:294-298. [DOI: 10.1016/ j. aott.2018. 02.012].

10. Ali N, Ahmad Mir N, Ahmad Dar T, Nawaz Rather M, Ahmad Mir W, S S, Maajid S. Outcome of Extra-Articular Distal Humerus Fractures Fixed by Single Column Extra-Articular Distal Humerus Locking Compression Plate Using Triceps Sparing Postero-Lateral Approach. Bull Emerg Trauma. 2018 Oct;6[4]:306-312. DOI: 10.29252/beat-060406.

11. Illical EM, Farrell DJ, Siska PA, Evans AR, Gruen GS, Tarkin IS. Comparison of outcomes after triceps split versus sparing surgery for extra-articular distal humerus fractures. Injury. 2014; 45[10]:1545-8. DOI: 10.1016/j.injury.2014.04.015.

12. Solarz MK, Patel MK, Struk AM, Matthias R, King JJ, Wright TW, Schoch BS. A Clinical Comparison of Triceps-Sparing and Triceps-Detaching Approaches for Revision Total Elbow Arthroplasty. J Hand Surg Am. 2020 Jan; 45[1]: 66.e1-66.e6. DOI: 10.1016/j.jhsa.2019.05.002.

13. Kokly S, Castagna A, Aarabi M. Triceps-sparing Posterior Approach for Supracondylar Humeral Fracture in Children. Arch Bone Jt Surg. 2019 Sep; 7[5]:416-421. PMID: 31742217.

14. Lu S, Zha YJ, Gong MQ, Chen C, Sun WT, Hua KH, Jiang XY. Olecranon osteotomy vs. triceps sparing for open reduction and internal fixation in treatment of distal humerus intercondylar fracture: a systematic review and meta-analysis. Chin Med J [Engl]. 2021; 134[4]:390-397. DOI: 10.1097/CM9. 0000000000001393.

15. Meijering D, Boerboom AL, Gerritsma CLE, The B, van den Bekerom MPJ, van der Pluijm $\mathrm{M}$, et al.; Study group. Prospective cohort study comparing a triceps-sparing and triceps-detaching approach in total elbow arthroplasty: a protocol. BMJ Open. 2021 May 5; 11[5]: e046098. DOI: 10.1136/bmjopen-2020-046098.

16. Zhang C, Zhong B, Luo CF. Comparing approaches to expose type $C$ fractures of the distal humerus for ORIF in elderly patients: six years clinical experience with both the tricepssparing approach and olecranon osteotomy. Arch Orthop Trauma Surg. 2014 Jun; 134[6]:803-11. DOI: 10.1007/ s00402- 014-1983-y. 

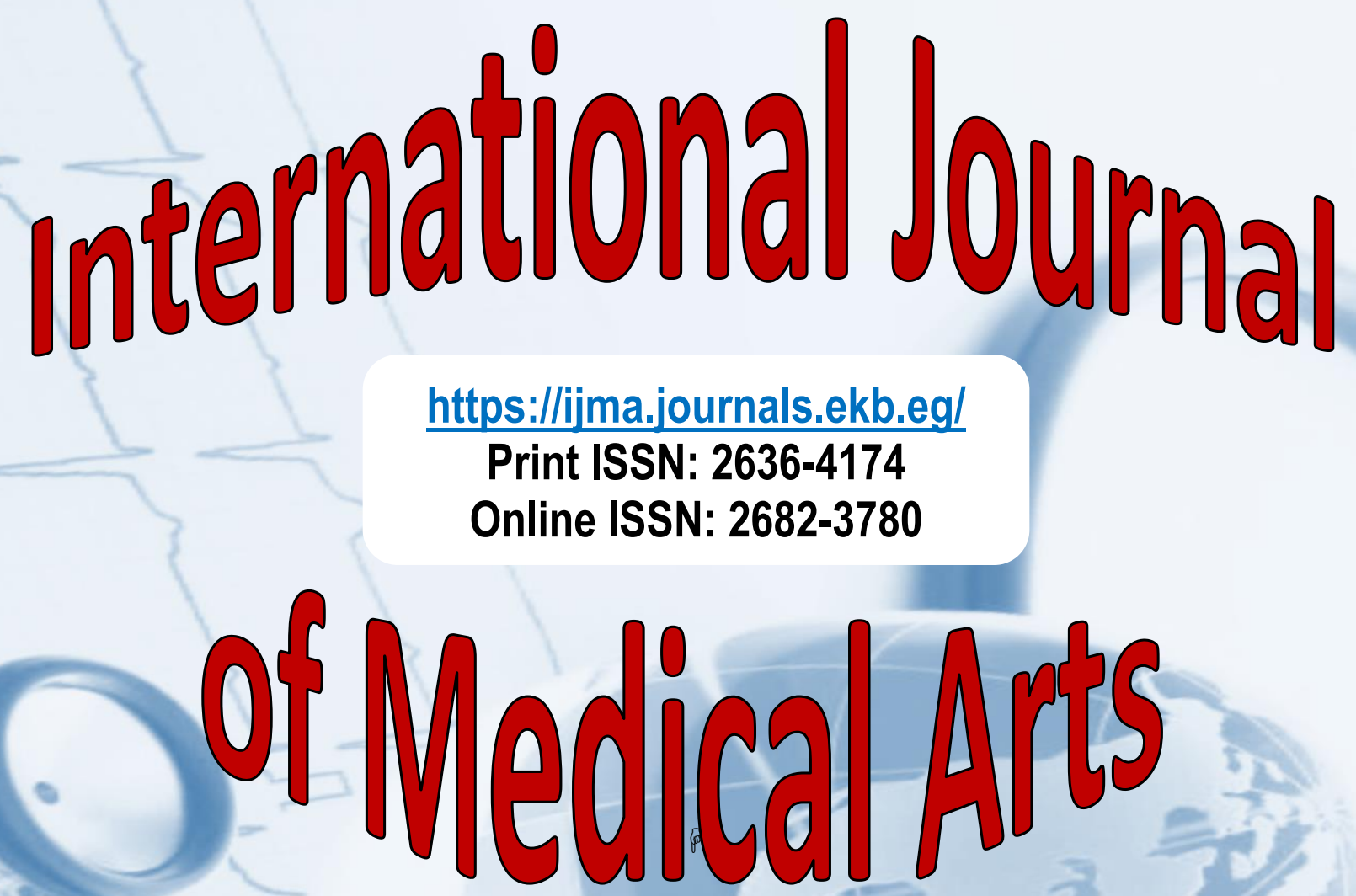